\title{
DUKUNGAN SUAMI BERHUBUNGAN DENGAN KUNJUNGAN ANTENATAL CARE
}

\author{
Nurhasanah* \\ *STIKes Muhammadiyah Cirebon \\ email: Khansa_noer@yahoo.com
}

\begin{abstract}
Background Most of the deaths of pregnant women are caused due to the delay in health personnel in detecting complications in the course of a mother's pregnancy. Several studies have shown that by doing a good pregnancy check can meet the basic needs of pregnant women, especially in increasing knowledge about the state of pregnancy, this can be a basic knowledge where a mother must be able to detect any complications, so that they can be immediately identified and handled properly. In this case the husband's support is needed in order to meet the psychological needs of a pregnant woman ..

Purpose to find the relationship between husband support as an independent variable with the mother's attitude in antenatal care visits as a dependent variable, each of which data is collected at the same time.

Methods This study uses analytic surveys using a cross sectional approach. With a sample of 30 pregnant women third trimester pregnant women and all mothers have a $\mathrm{MCH}$ book in the working area of the Astanagarib Health Center in Cirebon City.

The results showed that respondents have a good picture of husband support with a presentation value of (96.7\%), then most respondents visited the complete ANC which is equal to (66.7\%), after statistical calculations the Fisher test results obtained $p$ value of 0.767 (sig> 0.05) which means that Ha is rejected or there is no relationship of husband support for antenatal care visits.

The conclusion in this study there is no relationship of husband support for antenatal care visits.

Suggestions for adding other variables such as education, occupational level, and economy, health service factors to antenatal health awareness.
\end{abstract}

Keywords: Antenatal visit, husband support

\section{ABSTRAK}

Latar Belakang :Sebagian besar Kematian ibu hamil disebabkan karena terlambatnya tenaga kesehatan dalam mendeteksi adanya komplikasi pada perjalanan kehamilan seorang ibu. Beberapa penelitian membuktikan bahwa dengan melakukan pemeriksaan kehamilan dengan baik dapat memenuhi kebutuhan dasar ibu hamil tertutama dalam peningkatan pengetahuan akan keadaan kehamilannya, hal ini dapat menjadi pengetahuan dasar dimana seorang ibu harus mampu mendeteksi adanya komplikasi, sehingga dapat segera di ketahui dan ditangani dengan baik. Dalam hal ini dukungan suami sangat diperlukan dalam rangka pemenuhan kebutuhan psikologis seorang ibu hamil..

Penelitian ini bertujuan untuk mencari hubungan antara dukunga suami sebagai variabel bebas dengan sikap ibu dalam kunjungan antenatal care sebagai variabel terikat yang masing-masing datanya dikumpulkan dalam satu waktu yang sama.

Metode Penelitian ini menggunakan survey analitik denganmenggunakan pendekatan cross sectional. Dengan sampel sebanyak 30 ibu hamil ibu hamil trimester III dan semua ibu memiliki buku KIA yang berada di wilayah kerja Puskesmas Astanagarib Kota Cirebon.

Hasil penelitian didapatkan reponden memiliki gambaran dukungan suami baik dengan nilai presentasi sebesar (96,7\%), kemudian sebagian besar responden melakukan kunjungan ANC secara lengkap yakni sebesar $(66.7 \%)$, setelah dilakukan perhitungan secara statistic didapatkan data hasil uji Fisher didapat $p$ value sebesar 0,767 (sig > 0,05) yang bermakna Ha ditolak

Kesimpulan dalam penelitian ini tidak adanya hubungan dukungan suami terhadap kunjungan antenatal care.

Saran untuk menambahkan variabel lainnya seperti pendidikan, tingkat pekerjaan, dan ekonomi, faktor pelayanan kesehatan terhadap kesadaran kesehatan pada antenatal.

Kata kunci : Kunjungan Antenatal, Dukungan suami 


\section{PENDAHULUAN}

Upaya dalam peningkatan kesehatan ibu telah dilakukan baik ditingkat nasional maupun internasional.Ditingkat internasional (WHO) memperkirakan 585.000 perempuan meninggal setiap hari akibat komplikasi dan persalinan. saat ini Indonesia, pada 2015 AKI masih tergolong tinggi 4.999 dan pada 2016 turun menjadi 4.912 kemudian pada 2017 menjadi 1712. Walaupun telah terjadi penurunan sangat berarti pada tahun 2015 yaitu 4.999 dan pada 2016 turun menjadi 4.912 kemudian pada 2017 menjadi 1712, Menurut Profil kesehatan Provinsi Jawa Barat di tahun 2017 AKI di Provinsi Jawa Barat sebanyak 76,03 per 100.000 $\mathrm{KH}$, jika dibandingkan dengan proporsi AKI tahun 2017 yang ditargetkan maka AKI di Provinsi Jawa Barat sudah berada dibawah target nasional (MDG's) tahun 2015. (Profil Kesehatan Provinsi Jawa Barat, 2017)

Di Kota Cirebon pada tahun 2015 terdapat kematian ibu sebanyak 4 orang per 5400 kelahiran hidup, dan pada tahun 2014 terdapat kematian ibu sebanyak 4 orang per 5483 kelahiran hidupMenurut Depkes Kota Cirebon, cakupan K4 target Depkes 95\% dan target SPM Kota Cirebon sebesar 85\% sedangkan cakupan K4 sebesar 93,26\%. Pada tahun 2015, di Kota Cirebon menunjukan bahwa cakupan K4 secara keseluruhan sebesar 93,26\%, bila dibandingkan tahun 2014 (90,50\%). Mengalami kenaikan. K4 dengan kisaran tertinggi ada di kelurahan Kecapi Puskesmas Larangansebesar $104,19 \%$ dan terendah di kelurahan Pekalipan Puskesmas Astanagarib 67,21 \%. Jika dilihat berdasarkan SPM Perwalkot Kota Cirebon untuk target K4 sebesar $85 \%$, dapat disimpulkan bahwa hasil cakupan sudah mencapai target sedangkan jika dibandingkan dengan target Depkes 95\% pada tahun 2015 maka cakupan K4 belum mencapai target.Salah satu upaya untuk mengatasi permasalahan yang diakibatkan oleh resiko kehamilan adalah melakukan kunjungan pemeriksaan kehamilan atau antenatal care (Profil Dinas Kesehatan Kota Cirebon, 2016).

Faktor-faktor yang berpengaruh terhadap kunjungan Antenatal Care pada ibu hamil diantaranya meliputi adalah faktor pengetahuan, dukungan suami, pendidikan, setatus pekerjaan, dan paritas.(Depkes,2001)

\section{METODE PENELITIAN}

Jenis penelitian yang di gunakan adalah penelitian survei analitik. Metode penelitian survey analitik dimana akan dicari hubungan antara dukungan suami sebagai variabel bebas dengan sikap ibu dalam kunjungan antenatal care sebagai variabel terikat yang masing-masing datanya dikumpulkan dalam satu waktu yang sama.Penelitian ini menggunakan pendekatan cross sectional. (notoatmodjo,2010)

Sampel dalam penelitian ini adalah ibu hamil trimester III dan semua ibu memiliki buku KIA yang berada di wilayah kerja Puskesmas Astanagarib Kota Cirebon.

Sumber data yang digunakan adalah data primer dan data skunder, instrument dalam penelitian ini terbagi menjadi 2 (dua) macam intrumen, yaitu instrument data primer dengan menyebarkan kuesioner dan instrument data sekunder dengan angket, pengambilan data dilakukan secara crossectional, dengan metode wawancara kepada masing-masing ibu hamil dan melihat secara sekunder jumlah kunjungan antenatal pada buku KIA masing-masing ibu hamil.

Analisis data yang dilakukan adalah analisa univariat dan analisa data bivariat ,Analisis bivariat ini menggunakan uji Chi Square apabila memenuhi syarat, namun apabila tidak memenuhi syarat maka digunakan uji Fisher sebagai uji alternatifnya (Dahlan, 2011).

\section{HASIL DAN PEMBAHASAN \\ Hasil Analisis Univariat \\ Gambaran Dukungan Suami}

Tabel 1.

Distribusi Frekuensi Dukungan Suami dalam Antental Care

\begin{tabular}{lcc}
\hline $\begin{array}{c}\text { Dukungan } \\
\text { Suami }\end{array}$ & $\begin{array}{c}\text { Frekuensi } \\
(\mathrm{n})\end{array}$ & $\begin{array}{c}\text { Presentase } \\
(\%)\end{array}$ \\
\hline Tidak Baik & 1 & $3.3 \%$ \\
Baik & 29 & $96.7 \%$ \\
\hline Total & 30 & $100 \%$ \\
\hline
\end{tabular}

Tabel diatas menunjukan bahwa mayoritas reponden memiliki gambaran dukungan suami baik $(96,7 \%)$, sementara hanya $(3,3 \%)$ responden yang memiliki dukungan suami tidak baik. Sehingga dapet disimpulkan bahwa dukungan suami mempengaruhi ibu melakukan kunjungan ANC, semakin tinggi dukungan suami semakin termotivasi ibu melakukan kunjungan ANC

\section{Gambaran Kunjungan Antenatal}

Berdasarkan tabel diatas dapat dijelaskan bahwa sebagian bsar responden melakukan kunjungan ANC sebanyak 4 kali selama kehamilannya yakni sebesar (66.7\%), dan hanya 7 responden $(23.3 \%)$ yang melakukan kunjungan ANC kurangd ari 4 kali. 
Tabel 2.

Distribusi Frekuensi Kunjungan Antental Care

\begin{tabular}{lcc}
\hline $\begin{array}{c}\text { Jumlah } \\
\text { Kunjungan ANC }\end{array}$ & Frekuensi (n) & $\begin{array}{c}\text { Presentase } \\
(\%)\end{array}$ \\
\hline Lengkap & 23 & $76.7 \%$ \\
Tidak lengkap & 7 & $23.3 \%$ \\
\hline Total & 30 & $100 \%$ \\
\hline
\end{tabular}

\section{Hasil Analisis Bivariat}

Berdasarkan tabel 3 dapat dilihat hasil hubungan Antara kedua variabel, yakni dukungan suami dan kunjungan antenatal care sebanyak 1 responden memiliki dukungan tidak baik, tetapi melakukan kunjungan antenatal care lebih dari 4 kali. Sedangkan 29 responden lainnya memiliki dukungan suami yang baik. Sebanyak $22(75,9 \%)$ responden yang melakukan kunjungan antenatal care lebih dari 4 kali dan $7(24,1 \%)$ responden lainnya yang melakukan kunjungan antenatal care kurang dari 4 kali. Sedangkan hasil uji Fisher didapat $p$ value sebesar 0,767 (sig >0,05) yang bermakna $\mathrm{Ha}$ ditolak atau tidak adanya hubungan dukungan suami terhadap kunjungan antenatal care.

Tabel 3.

Hubungan Dukungan Suami dengan Kunjungan Antenatal

\begin{tabular}{cccc}
\hline \multirow{2}{*}{$\begin{array}{c}\text { Dukungan } \\
\text { Suami }\end{array}$} & \multicolumn{2}{c}{ Kunjungan Antenatal } & \\
\cline { 2 - 3 } & $\begin{array}{c}\text { Tidak } \\
\text { Lengkap }\end{array}$ & Lengkap & Jumlah \\
\hline \multirow{2}{*}{ Tidak baik } & 0 & 1 & 1 \\
& $0.0 \%$ & $100.0 \%$ & $100.0 \%$ \\
Baik & 7 & 22 & 29 \\
& $24.1 \%$ & $75.9 \%$ & $100.0 \%$ \\
\hline \multirow{2}{*}{ Total } & 7 & 23 & 30 \\
& $23.3 \%$ & $76.7 \%$ & $100.0 \%$ \\
\hline
\end{tabular}

\section{PEMBAHASAN}

Sebegaimana keputusan Menteri Kesehatan RI Nomor 1457/Menkes/SK/X/2003 tentang Standar Pelayanan Minimal di bidang kesehatan di Kabupaten atau Kota sebagai salah satu usaha untuk menurunkan AKI dan AKB melalui pelayanankesehatan ibu dan anak berupa cakupan kunjungan antenatal. (Saifudin, 2002). Kunjungan antenatal pada ibu hamil banyak dipengaruhi oleh beberapa faktor, baik secara internal maupun eksternal. Peneliti pada awal dugaan bahwa faktor eksternal yaitu dukungan suami mempunyai pengaruh paling besar, namun setelah dilakukan pengambilan data kemudia dianalisa meggunakan metode kuantitatif, ternyata faktor dukungan suami tidak mempengaruhi kunjungan antenatal ibu hamil.

Hal ini dapat dilihat dari hasil penelitian pada tabel.3 bahwa walaupun ibu hamil kurang mendapatkan dukungan dari suami, namun dapat melakukan pemeriksaan kehamilan dengan baik. Hal ini membuktikan bahwa ibu hamil sebagain besar sudah menyadari bahwa pemenuhan kebutuhan akan infromasi keadaan dirinya dan bayinya lebih baik,bahwa dengan melakukan pemeriksaan kehamilan akan menambah infromasi mengenai keadaan dirinya dan bayinya. Sesuai dengan hasil penelitian oleh (Artika Dewi, 2017) aspek yang berhubungan signifikan dengan kunjungan antenatal adalah pengetahuan ibu, dibandingkan dengan umur, pendidikan, paritas dan pekerjaan. Hal ini membuktikan bahwa pengetahuan seorang ibu memiliki peranan penting dalam adanya perubahan perilaku mengenai kedasaran kesehatannya.

\section{KESIMPULAN}

Dalam penelitian ini tidak adanya hubungan bermakna antara dukungan suami terhadap kunjungan antenatal care di Wilayah Kerja Puskesmas Astanagarib. Peneliti meyakini bahwa terdapat variabel lain yang lebih memiliki pengaruh signifikan terhadap frekuensi kunjungan ANC pada komunitas ibu hamil di wiliyah Puskesmas Astanagarib Kota Cirebon, seperti tingkat pendidikan, tingkat pekerjaan, dan ekonomi, faktor pelayanan kesehatan, dan lain sebagainya.

\section{SARAN}

Penelitian selanjutnya untuk menambahkan variabel lainnya seperti pendidikan, tingkat pekerjaan, dan ekonomi, faktor pelayanan kesehatan terhadap kesadaran kesehatan pada antenatal, untuk kesempurnaan hasil yang akan datang.

\section{DAFTAR PUSTAKA}

Aisyah, R. D., Rusmariana, A., \& Mujiati, D. (2015). Frekuensi Kunjungan ANC (Antenatal Care) Pada Ibu Hamil Trimester III. Jurnal IImiah Kesehatan (JIK), 8(2). 239-243

Artika Dewi (2017). Faktor-faktor yang mempengaruhi Kunjungan K4 Di Puskesmas Baqa Kota Samarinda Tahun 2016. Jurnal IImiah Kesehatan Diagnosis Vol.10 (3)

Dahlan, M. S. (2011). Statistik untuk kedokteran dan kesehatan. Penerbit Salemba.

Dewi, M. S. (2015). Hubungan Dukungan Keluarga Terhadap Frekuensi Kunjungan Antenatal 
Care pada Komunitas Ibu Slum Area Kelurahan Selapajang Jaya Kota Tangerang.

Depkes, R. I. (2001). Standar pelayanan kebidanan. Jakarta: Kemenkes RI.

Fitrayeni, F., Suryati, S., \& Faranti, R. M. (2017). Penyebab Rendahnya Kelengkapan Kunjungan Antenatal Care Ibu Hamil di Wilayah Kerja Puskesmas Pegambiran. Jurnal Kesehatan Masyarakat Andalas, 10(1), 101-107.

Hargi, J. P. (2013). Hubungan dukungan suami dengan sikap ibu dalam pemberian ASI eksklusif di Wilayah Kerja Puskesmas Arjasa Kabupaten Jember.

Khasanah, F. Gambaran Kunjungan Antenatal Care di Puskesmas Pondok Jagung Tangerang Selatan (Bachelor's thesis, UIN Syarif Hidayatullah Jakarta: Fakultas Kedokteran dan IImu Kesehatan, 2017).

Marsitha, A. A. Hubungan Tingkat Pengetahuan Dan Dukungan Suami Terhadap Kunjungan Antenatal Care Di Wilayah Kerja Puskesmas Perumnas II. Jurnal Mahasiswa PSPD FK Universitas Tanjungpura, 5(1)

Melati, R., \& Raudatussalamah, R. (2012). Hubungan Dukungan Sosial Suami Dengan Motivasi Dalam Menjaga Kesehatan Selama Kehamilan. Jurnal Psikologi, 8(2), 111-118.
Notoatmodjo, S. (2010). Metododologi Penelitian Kesehatan.

Saifudin. (2002). Buku Panduan Praktis Pelayanan Kesehatan Maternal dan Neonatal, Yayasan Bina Pustaka Sarwono Prawiraharjo, Jakarta.

Subratha, H. F. A., \& Kartiningsih, N. W. M. (2018). Hubungan Dukungan Suami Dengan Kunjungan Antenatal Care (Anc) Pada lbu Hamil Di Kabupaten Tabanan. Jurnal Medika Usada, 1(1).

Susilawati, S., Karyanah, Y., \& Kusumapradja, R. (2014). Hubungan Pengetahuan Ibu Hamil Tentang Kehamilan Dengan Keteraturan Pemeriksaan Kehamilan di Puskesmas Balaraja Kabupaten Tangerang Banten. Indonesian of Health Information Management Journal (INOHIM), 2(2), 82-89.

Wulandari, M. D. (2017). Hubungan Dukungan Suami dengan Kepatuhan Pemeriksaan Antenatal Care pada Ibu Hamil di Puskesmas Kasihan II Bantul Yogyakarta (Doctoral dissertation, STIKES Jenderal Achmad Yani Yogyakarta)

Yanti, Y. E. (2015). Hubungan pengetahuan ibu dan dukungan suami pada ibu hamil terhadap keteraturan kunjungan antenatal care (anc) di puskesmas wates lampung tengah tahun 2014. Jurnal Kebidanan Malahayati, 1(2) 